\title{
ESTUDO DE CASO: ANÁLISE DAS PROPRIEDADES FÍSICAS E MORFOLÓGICAS DE UM SCM ASSOCIADO À GERAÇÃO DE EVENTOS SEVEROS NO RIO GRANDE DO SUL ENTRE 8 E 9 DE AGOSTO DE 2011
}

\author{
Gustavo Rasera ${ }^{1}$, Vagner Anabor ${ }^{2}$ \\ 1Universidade Federal de Santa Maria, grasera13@gmail.com \\ ${ }^{2}$ Universidade Federal de Santa Maria, vanabor@gmail.com
}

\section{RESUMO}

Foi realizada uma análise de um SCM associado à geração de eventos severos (ES) em 48 municípios do Rio Grande do Sul (RS) entre os dias 8 e 9 de agosto de 2011. Este SCM teve duração de 11,5 horas sendo bastante estacionário, com um pequeno deslocamento zonal de oeste para leste. Sua iniciação ocorreu no dia 08/08/2011 às 2240 UTC (128.304 km²) com o centro de massa sobre o oeste catarinense. Durante essa fase, o SCM foi responsável por gerar ES em 42 municípios. A fase de maturação ocorreu na região nordeste do RS no dia 09/08/2011 às 0240 UTC (332.144 km²). Até atingir a maturação os demais municípios foram atingidos por ES. Por fim, a dissipação ocorreu no nordeste de Santa Catarina no dia 09/08/2011 às 1010 UTC $\left(70.816 \mathrm{~km}^{2}\right)$.

\section{SUMMARY}

An analysis was conducted of a MCS associated with the generation of severe weather events (SWE) in 48 municipalities of Rio Grande do Sul state (RS) between 8 and 9 of August 2011. This MCS lasted 11.5 hours, being quite stationary, with a small zonal displacement west to east. Its initiation occurred on 8/8/2011 at 2240 UTC $\left(128,304 \mathrm{~km}^{2}\right)$, with the center of mass over west of Santa Catarina (SC) state. During this phase the MCS was responsible for generating SWE in 42 municipalities. The maturation phase occurred in northeastern region of RS on 8/9/2011 at 0240 UTC $\left(332,144 \mathrm{~km}^{2}\right)$. Until it reaches the maturation the others 6 municipalities were affected by SWE. Finally, the dissipation occurred in the northeast of SC on 8/9/2011 at 1010 UTC.

\section{INTRODUÇÃO}

Os SCM são constituídos por um aglomerado de nuvens convectivas e que apresentam área com contínua precipitação, que pode ser parcialmente estratiforme e parcialmente convectiva, possuem formas variadas (HOUZE, 1993; MACHADO; ROSSOW, 1993). Devido à convecção inerente a esse tipo de sistema as correntes ascendentes e subsidentes tendem a ter uma forte componente aumentando a chance de ocorrência de um evento severo (ES).

Dada a importância dos SCM na geração de ES sobre o RS, este estudo tem como objetivo analisar as propriedades físicas e morfológicas de um SCM que contribuiu para a geração de ES sobre 48 municípios do RS, entre os dias 8 e 9 de agosto de 2011.

\section{MATERIAL E MÉTODO}

Para a confecção deste estudo, foram utilizadas imagens do canal 4 (infravermelho termal) do satélite GOES 13. Essas imagens foram realçadas através de um rastreador que 
utiliza linguagem Python, que identificou áreas com temperaturas de brilho inferiores ou iguais à $-55^{\circ} \mathrm{C}$. Por fim, foi utilizado o banco de dados da Defesa Civil do RS para a obtenção dos municípios que reportaram eventos severos no dia de atuação do SCM analisado.

\section{RESULTADOS E DISCUSSÃO}

Nas imagens anteriores ao início do SCM, foi possível observar disparos convectivos isolados no sul do Paraguai 3,5 horas antes. Essas células convectivas tiveram um deslocamento para sudeste aumentando de tamanho e se agrupando, dando início ao SCM analisado.

A Fig. 1 apresenta a evolução espacial e temporal do SCM. Teve início às 2240 UTC do dia 8 quando atingiu uma área de $100.000 \mathrm{~km}^{2}$ com temperaturas maiores ou iguais à $-55^{\circ} \mathrm{C}$. Nesse momento cobriu boa parte de Santa Catarina e o noroeste do RS, gerando vendaval em 40 municípios e enxurrada em 2 municípios. Nas 2 horas seguintes foram atingidos mais 6 municípios ( 3 - enchente, 2 - vendaval e 1 - enxurrada). Até às 0440 UTC do dia 9 o SCM apresentou grande desenvolvimento para sudeste atingindo a fronteira do RS com o Uruguai e regiões do Oceano Atlântico. A partir das 0740 UTC do dia 8 fica evidente o deslocamento para norte, atingindo o estado do Paraná. Através da sobreposição das áreas do SCM durante seu ciclo de vida pode se observar que a maior parte do RS foi atingida por esse SCM.

O deslocamento zonal do SCM para leste vai ao encontro de diversos autores que estudaram SCM à leste dos Andes, na América do Sul subtropical (NICOLINI et al., 2002; ANABOR et al., 2008).

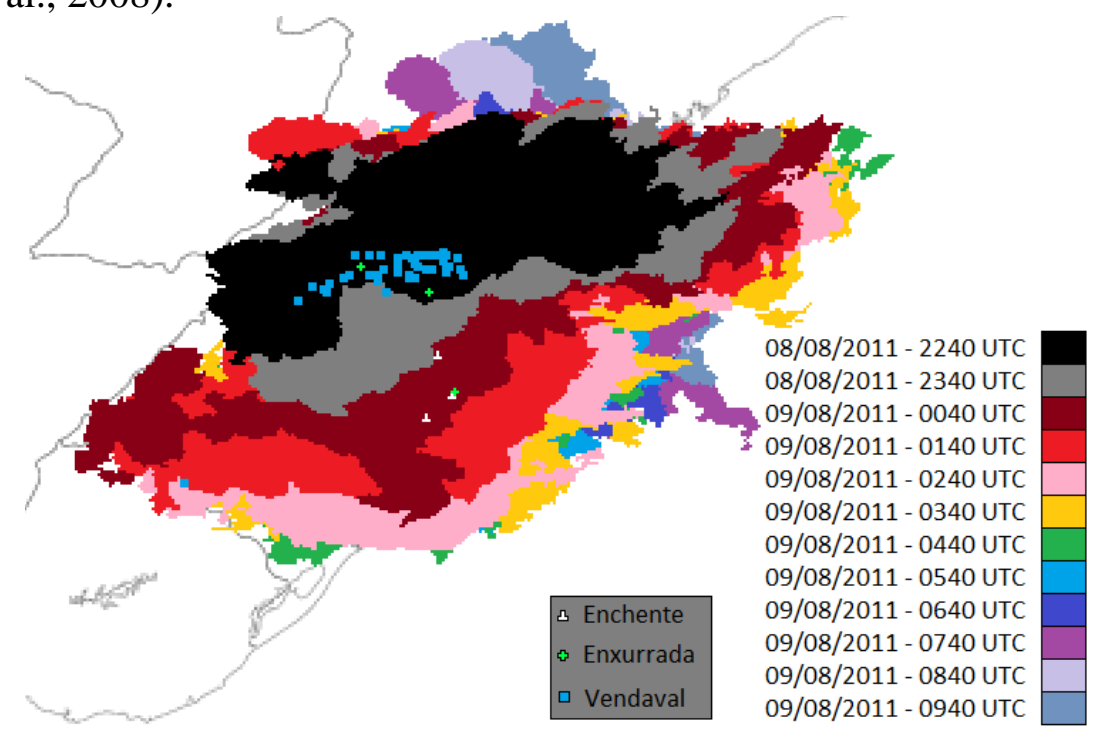

Figura 1 - Sobreposição das áreas do SCM, a cada hora, desde a sua iniciação até o momento de dissipação.

\section{CONCLUSÕES} sobre o RS.

Este estudo permitiu aos autores analisar um SCM causador de grande impacto

As imagens anteriores mostraram que o SCM teve início a partir de células convectivas localizadas no sul do Paraguai. Às 2240 UTC do dia 08/08/2011 teve início o 
SCM, quando este superou os $100.000 \mathrm{~km}^{2}$ gerando ES em $88 \%$ dos munícipios afetados durante o estudo. Alcançou sua máxima extensão às 0240 UTC do dia $9\left(332.112 \mathrm{~km}^{2}\right) \mathrm{e}$ voltou a ter menos de $100.000 \mathrm{~km}^{2}$ às 1010 UTC do dia 9, quando se deu sua dissipação. A trajetória do SCM foi para sudeste no início e posteriormente para norte, sendo predominantemente zonal.

Posteriormente uma análise sinótica será realizada para que seja possível um entendimento mais aprofundado acerca do SCM estudado.

\section{AGRADECIMENTOS}

Os autores agradecem à CAPES pelo auxílio financeiro.

\section{BIBLIOGRAFIA}

ANABOR, V., D. J. Stensrud, and O. L. L. de Moraes, 2008: Serial upstreampropagating mesoscale convective system events over southeastern South America. Mon. Wea. Rev., $136,3087-3105$.

HOUZE, R.A. Mesoscale convective systems. In Cloud dynamics. Academic Press, Inc, v.53, p. 334-404, 1993.

MACHADO, L.A.T.; ROSSOW, W.B. Structural characteristics and radiative of tropical cloud clusters. Monthly Weather Review, v.121, n.12, p.3234-3260, 1993.

NICOLINI, M.; SAULO, A.C.; TORRES, J.C.; SALIO, P.: Enhanced precipitation over Southeastern South América related to strong low-level jet events during austral warm season. Meteorologica, Special Issue for the South American Monsoon System, v.27, p.5969, 2002. 